\title{
Comparison of disposable sutureless silicone ring and traditional metal ring in 23-gauge vitrectomy combined with cataract surgery
}

This article was published in the following Dove Press journal:

Clinical Ophthalmology

29 June 2011

Number of times this article has been viewed

\author{
Jian-Guo Wu \\ Rui-Hua Wei \\ Ai-Hua Liu \\ Xiao-Xu Zhou \\ Guo-Ling Sun \\ Xiao-Rong Li \\ Tianjin Medical University Eye Center, \\ Tianjin, China
}

Background: The purpose of this prospective, interventional, comparative case series was to evaluate the efficiency and feasibility of a disposable sutureless silicone lens ring for corneal contact lens stabilization during combined 23-gauge vitrectomy and cataract surgery.

Methods: We developed a ring consisting of a single silicone component with three footplates along the ring margin to fit cannulae for holding conventional contact lenses. Thirty eyes from 30 patients with cataract and vitreoretinal disease were included, and divided into two matched groups according to disease type and ring used. In Group A, we used a 23-gauge transconjunctival vitrectomy system and a disposable sutureless silicone lens ring $(n=15)$. In Group B, we used a 23 -gauge transconjunctival vitrectomy system and a conventional metal lens ring $(n=15)$. The main outcome measures were: time required for vitrectomy preparation, rate of intraoperative corneal limbus bleeding, and limbus scar rate at the final follow-up visit.

Results: Thirty cases were successfully completed. The average vitrectomy preparation time was less in Group A than in Group B $(P<0.01)$, and the average preparation time saved was 3.94 minutes. None of the Group A patients had intraoperative bleeding or postoperative scarring, whereas all 15 Group B cases had bleeding and five had scarring. There was a statistically significant difference between Group A and Group B for these complications $(P \leq 0.05)$.

Conclusion: This report demonstrates the advantages of using a sutureless silicone ring during combined 23-gauge vitrectomy and cataract surgery. Using this method could allow extra time for the surgeon to pay more attention to complex vitreoretinal procedures.

Keywords: pars plana vitrectomy, contact lens, silicone ring, cataract surgery

\section{Introduction}

Use of corneal contact lenses during vitrectomy has become indispensable because it offers an excellent view of the ocular fundus. In traditionally used systems, lenses are supported by a sutured ring with either two or four sutures. ${ }^{1}$ However, placement of these sutures is time-consuming, has the potential to cause bleeding, and increases the possibility of globe perforation.

To simplify suture procedures, Ikuno et al introduced the concept of a sutureless contact lens ring and designed a system comprising a stainless steel ring with two upright tabs $\left(180^{\circ}\right.$ apart), with a hook on the top and two elastic silicone bands ( $8 \mathrm{~mm}$ in diameter) to fix the ring to the eyelid speculum. ${ }^{2}$ Although this system was an improvement in comparison with suturing, the silicone bands hindered rotation of the globe and scleral depression.

Chalam et al designed a series of suture-free lens systems, including three aspheric plastic lenses, a standard wide-angle contact lens, and four footplates. ${ }^{3-7}$ However,
Tianjin Medical University Eye Center, 25I Fukang Road, Nankai District, Tianjin 300384, China

Tel +8602258280720

Fax +86022 25340682

Email wujg204329@sina.com 
these systems were easily displaced from the visual axis when the eyeball was tilted or when they came into contact with the lid margin or lid speculum.

Chong et al developed a system consisting of a single plastic ring with multiple concavities at the ring margin to fit a 25 -gauge cannula. ${ }^{8}$ This ring provided considerable stability to the contact lens system without obstructing the surgeon's visual field, even while using a top-heavy panoramic contact lens or when scleral depression was used for vitreous-based dissection. However, use of the 23-gauge cannula is now more popular.

We designed a flexible disposable sutureless silicone lens ring and observed its efficiency and feasibility in 23-gauge vitrectomy combined with cataract surgery. ${ }^{9}$

\section{Methods and materials Development of silicone ring}

The flexible ring is machined from clear or blue silicone and packaged individually after sterilization by autoclave. It has three footplates along the ring margin, and each footplate is designed to accommodate a cannula when the cannula is inserted $3.5 \mathrm{~mm}$ or $4.0 \mathrm{~mm}$ posterior to the limbus. Three transconjunctival cannulae can be inserted directly through the footplates and scleral wall to provide stable three-point fixation. The products were purchased from Tianjin Shijikangtai Medical Bioengineering Ltd (Tianjin, China).

\section{Surgical indications, groups, and techniques}

A prospective clinical investigation was performed to evaluate the feasibility and efficiency of a sutureless silicone ring for combined vitrectomy and cataract surgery. The study followed the tenets of the Declaration of Helsinki and was approved by the Tianjin Medical University ethics committee. All patients provided both verbal and written informed consent.

Thirty patients (16 men and 14 women) were enrolled in this project from September 2009 to January 2010, with surgical indications for 23-gauge vitrectomy limited to the epiretinal membrane $(n=8)$, idiopathic macular holes $(n=8)$, diabetic vitreous hemorrhage $(n=6)$, focal diabetic traction retinal detachment $(n=4)$, macular traction syndrome $(n=2)$, and macular edema secondary to central retinal vein occlusion $(n=2)$. The mean patient age \pm standard deviation was $62.91 \pm 8.33$ (range 52-76) years. Eyes were excluded if there was a history of vitrectomy, or other vitreoretinal pathologies, particularly peripheral abnormalities, extensive retinal detachment, or corneal opacities precluding adequate posterior visualization. The 30 patients were divided into two matched groups according to disease type and use of a silicone ring. The 23-gauge transconjunctival vitrectomy system (Alcon Ophthalmic Products Co Ltd, Shanghai, China) and a disposable sutureless silicone ring was used in Group A, and a transconjunctival vitrectomy system 23-gauge and conventional metal ring was used in Group B. All procedures were performed by the same experienced surgeon and recorded by video at Tianjin Medical University Eye Center from September 2009 through January 2010. Patients were followed up for a mean of 4 (range 3-6) months.

In Group A, after retrobulbar anesthesia with lidocaine $2 \%$ and conjunctival disinfection with povidone-iodine, phacoemulsification and aspiration were performed first through a $3.0 \mathrm{~mm}$ clear corneal incision. The 23-gauge transconjunctival vitrectomy system was inserted immediately after creation of a 23-gauge trocar cannula-angled incision at the pars plana. The trocar cannula system simultaneously fixed the silicone ring (supplementary video 1). All surgeries used the conventional planoconcave contact lens, $15^{\circ}$ prism contact lens, and panoramic contact lens. Core vitrectomy using the 23-gauge vitreous cutter was performed with intravitreal injection of triamcinolone acetonide to visualize the vitreous gel and to identify the location of vitreoretinal adhesions. If there was no posterior hyaloid detachment, one was created using a membrane spatula. In eyes with an epiretinal membrane, macular hole, or macular edema, the inner limiting membrane was removed using 23-gauge microforceps (supplementary video 2). In eyes with a focal traction retinal detachment caused by proliferative diabetic retinopathy, the fibrovascular membranes were cut and removed using the 23-gauge cutter. If the fibrovascular membranes were extensively adhering to the detached retina, membrane separation and dissection from the retina were performed using a membrane spatula. Peripheral vitrectomy, vitreous base shaving, and endolaser photocoagulation up to the anterior retina using a 23-gauge laser probe were performed under the panoramic contact lens. Endoillumination with scleral indentation helped to identify peripheral retinal pathologic features. Fluid-gas exchange was performed in eyes with a macular hole or traction retinal detachment by flushing with $50 \mathrm{~mL}$ of a premixed nonexpansile concentration of sulfur hexafluoride $20 \%$. Without moving the silicone ring, acrylic foldable intraocular lens implantation was performed through a clear corneal incision after completion of vitreoretinal surgery (supplementary video 3 ). After thorough re-examination of the ocular fundus, the operator simply removed all inserted instruments and concluded without 
sutures (supplementary video 4). Topical Tobra Dex ${ }^{\circledR}$ eye ointment (Alcon Laboratories, Hünenberg, Switzerland) was applied, and the eye was patched and shielded. Patients who had undergone fluid-gas exchange were instructed to remain face down for 3-7 days.

In Group B, a conventional metal ring (Alcon Ophthalmic Products Co Ltd) was used as a control. Vitrectomy preparation included five steps: retrobulbar anesthesia, conjunctival disinfection, phacoemulsification, limbus sutures to fix the metal ring, and three inserted trocars in the pars plana (supplementary video 5). An exception was the removal of the metal ring before intraocular lens implantation and hand-holding of the contact lens during re-examination of the ocular fundus. Other vitreoretinal procedures in Group B were similar to that of Group A.

\section{Data analysis}

Patient medical records and surgical notes were reviewed. The data collected included anatomical reduction, wound self-sealing, preoperative and postoperative best-corrected visual acuity measured by $\operatorname{LogMAR}$ at final follow-up visits, preoperative and postoperative intraocular pressure measured by noncontact tonometer at the day 1 , week 1 , month 1, and final follow-up visits, vitrectomy preparation time, total operating time, and intraoperative corneal limbus bleeding rates and postoperative limbus scar rates at final follow-up visits.

\section{Statistical analysis}

Statistical analysis was performed using SPSS11.5 software (SPSS Inc, Chicago, IL). Vitrectomy preparation time was analyzed using the paired-samples $t$-test. Intraoperative corneal limbus bleeding rates and postoperative limbus scar rates were analyzed using the Fisher Exact test. A level of $P<0.05$ was accepted as statistically significant.

\section{Results}

Surgery in all 30 eyes was completed using 23-gauge transconjunctival vitrectomy system instruments, and cataract surgeries with intraocular lens implantation were simultaneously performed. Fluid-air exchange followed by instillation of sulfur hexafluoride $20 \%$ or air tamponade alone was performed in eight eyes (8/30). No intraoperative complications occurred. At the end of surgery, 23-gauge sclerotomies in all 30 eyes were self-sealed without suture placement after removal of instruments. Anatomical reduction was achieved in all eyes with successful removal of an epiretinal membrane, inner limiting membrane, or both, reattachment of the detached retina, closure of the macular holes, or clearance of the clouded media. The mean preoperative visual acuity was 0.17 (range, 0.05-0.3) at the last follow-up visit and the mean visual acuity improved significantly to 0.52 (range $0.1-0.8, P<0.001)$. The mean preoperative intraocular pressure was $14.63 \pm 3.54$ (range 10-21) $\mathrm{mmHg}$, and the mean postoperative intraocular pressures at day 1 , week 1 , and the final visit were $14.72 \pm 5.15$ (range 9-32) $\mathrm{mmHg}, 14.53 \pm 3$ (range 8-23) $\mathrm{mmHg}$, and $13.84 \pm 2.47$ (range 9-18) $\mathrm{mmHg}$, respectively. There were no significant differences between preoperative and postoperative intraocular pressure at any follow-up visits $(P>0.05)$.

The average vitrectomy preparation time was $6.40 \pm 0.95$ minutes in Group A and $10.34 \pm 1.13$ minutes in Group B. The difference was statistically significant $(\mathrm{t}=-59.00$, $P<0.01$ ) between Group A and Group B. Compared with the conventional metal lens ring used in Group B, use of this newly designed sutureless silicon lens ring could help to save an average 3.93 minutes of operation time.

No intraoperative subconjunctival hemorrhage at limbus was observed in Group A (0/15), while a small amount of subconjunctival hemorrhaging at limbus could be seen in all cases in Group B (15/15). This difference was statistically significant $(P<0.01)$. The incidence of limbal scarring was 0 in Group A (0/15), but limbal scars were found in five diabetic cases in Group B at the final visit $(33 \%, 5 / 15)$ and this difference was statistically significant $(P<0.05)$.

\section{Discussion}

With the development of surgical instruments and surgical skills, vitreous surgery has been simplified from the seven steps in conventional 20-gauge vitrectomy to three steps in advanced 25-gauge, 23-gauge, and recent 20-gauge selfsealing cannula system vitrectomy. ${ }^{10-12}$ In this study, we successfully completed 23-gauge vitrectomy in two steps by using a sutureless silicone ring, which achieved the same operative efficacy but with shorter preparation time and less ocular surface trauma compared with the Oshima et al study using 27-gauge vitrectomy and a wide-angle viewing system (Table 1). ${ }^{13}$ Compared with other intelligent suturefree lens forms, such as the Oculus BIOM and hand-held lens systems, the silicone contact lens ring is very cheap and easier to use.

To avoid the fuzzy halo round the intraocular lens margin hindering the surgeon's view, we chose to insert the intraocular lens at the end of the surgery and not at the end of phacoemulsification. The ring is anchored at three 
Table I Simplification of vitrectomy techniques

\begin{tabular}{|c|c|c|c|c|}
\hline Surgery procedure & $\begin{array}{l}\text { Conventional } \\
20 \text {-gauge } \\
\text { vitrectomy }\end{array}$ & $\begin{array}{l}25-, 23-, \text { and recent } \\
20 \text {-gauge self-sealing } \\
\text { cannula systems } \\
\text { vitrectomy }\end{array}$ & $\begin{array}{l}25-, 23-, \text { and recent } \\
20 \text {-gauge self-sealing } \\
\text { cannula systems } \\
\text { vitrectomy + silicone ring }\end{array}$ & $\begin{array}{l}\text { 27-gauge vitrectomy + } \\
\text { the wide-angle viewing } \\
\text { system }\end{array}$ \\
\hline Cutting off the conjunctival & $\bullet$ & & & \\
\hline $\begin{array}{l}\text { Electrical coagulation of } \\
\text { the Sclera }\end{array}$ & $\bullet$ & & & \\
\hline $\begin{array}{l}\text { Suturing and placing the } \\
\text { contact lens ring }\end{array}$ & $\bullet$ & $\bullet$ & & \\
\hline $\begin{array}{l}\text { Fixing the infusion } \\
\text { cannula, optic cannula } \\
\text { and operation cannula }\end{array}$ & $\bullet$ & $\bullet$ & $\bullet$ & $\bullet$ \\
\hline $\begin{array}{l}\text { Vitrectomy and other } \\
\text { operation inner the globe }\end{array}$ & $\bullet$ & $\bullet$ & $\bullet$ & $\bullet$ \\
\hline Removing the contact ring & $\bullet$ & & & \\
\hline $\begin{array}{l}\text { Suturing the scleral and } \\
\text { conjunctival incision }\end{array}$ & $\bullet$ & & & \\
\hline Total & 7 steps & 3 steps & 2 steps & 2 steps \\
\hline Comments & $\begin{array}{l}\text { Longer vitrectomy } \\
\text { preparation time, larger } \\
\text { ocular surface trauma }\end{array}$ & $\begin{array}{l}\text { Shorter preparation time, } \\
\text { minor ocular surface trauma }\end{array}$ & $\begin{array}{l}\text { Further reduced preparation } \\
\text { time, further reduced ocular } \\
\text { surface trauma }\end{array}$ & $\begin{array}{l}\text { Further reduced } \\
\text { preparation time, } \\
\text { further reduced ocular } \\
\text { surface trauma }\end{array}$ \\
\hline
\end{tabular}

points by cannulae inserted directly through the footplates and scleral wall when using 23-gauge vitrectomy combined with cataract surgery. This provides considerable stability to the contact lens system. Even in cases which require scleral depression, there is still enough clearance between the edge of this ring and the lid speculum or lid margin to accommodate the scleral depressor without touching the ring. Furthermore, time-consuming suturing, corneal limbus bleeding, and scarring may be avoided.

In addition to reduced vitrectomy preparation time and less ocular surface trauma, this silicone ring offers the advantage of the Chalam suture-free lens system and Chong's selfsealing lens ring fitting the 25 -gauge cannula. ${ }^{3-8}$ The model we have described provides considerable flexibility when performing combined anterior-posterior segment surgery, such as injection of the artificial lens and anterior chamber wash while the ring is still in place. This feature is very useful for thorough re-examination of the ocular fundus at the end of combined surgery, or redo vitreoretinal operation if a complication occurs.

\section{Conclusion}

In conclusion, the current results confirm the preliminary feasibility of the sutureless silicone ring and 23-gauge transconjunctival vitrectomy system in selected cases. This sutureless technique, with no intraoperative bleeding, no postoperative limbus scar, and shorter vitrectomy preparation time will enable the surgeon to pay more attention to complex vitreoretinal diseases.

\section{Acknowledgment}

The authors thank Professor Melvin D Trousdale, Doheny Eye Institute, Keck School of Medicine, University of Southern California, for revising the manuscript.

\section{Disclosure}

The authors report no conflicts of interest in this work.

\section{References}

1. Lewis JM, Ohji M, Tano Y. A technique for contact lens fixation during vitreous surgery. Ophthalmic Surg Lasers. 1996;27(10):891-893.

2. Ikuno Y, Ohji M, Kusaka S, et al. Sutureless contact lens ring system during vitrectomy. Am J Ophthalmol. 2002;133(6):847-848.

3. Chalam KV, Patel CC, Shah VA. Newly designed self-retaining contact lens for vitreous surgery. Am J Ophthalmol. 2003;135(4):544-546.

4. Shah VA, Chalam KV. Suction-assisted one-piece self-retaining wide-angle contact lens for vitrectomy. Ophthalmic Res. 2003;35(3): 170-172.

5. Shah VA, Chalam KV. Self-stabilizing wide-angle contact lens for vitreous surgery. Retina. 2003;23(5):667-669.

6. Shah VA, Chalam KV. Newly designed self-retaining prism contact lens for vitreous surgery. Retina. 2003;23(5):721-722.

7. Chalam KV, Murthy RK. Reusable sutureless silicone ring for housing contact lens during vitreo-retinal surgery. Retina. 2008;28(10):1550-1551.

8. Chong LP, McCormick M, Deboer C, Barnes A. A self-stabilizing lens ring for 25-gauge vitrectomy surgery. Am J Ophthalmol. 2007;143(2): 350-351.

9. Wu J, Zhou X, Sun G, et al. Disposable sutureless silicone contact lens ring for use with a self-sealing cannula system during vitrectomy. Retina. 2010;30(4):705-707. 
10. Fujii GY, De Juan E Jr, Humayun MS, et al. A new 25-gauge instrument system for transconjunctival sutureless vitrectomy surgery. Ophthalmology. 2002;109(10):1807-1812.

11. Fine HF, Iranmanesh R, Iturralde D, Spaide RF. Outcomes of 77 consecutive cases of 23-gauge transconjunctival vitrectomy surgery for posterior segment disease. Ophthalmology. 2007;114(6):1197-1200.
12. Akira N, Masayo K, Tetsuhiko O, et al. A new self-sealing cannula system for 20-gauge vitrectomy: outcomes of 247 consecutive cases. Retina. 2008;28(5):778-781.

13. Oshima Y, Wakabayashi T, Sato T, Ohji M, Tano Y. A 27-gauge instrument system for transconjunctival sutureless microincision vitrectomy surgery. Ophthalmology. 2010;117(1):93.e2-102.e2.

\section{Publish your work in this journal}

Clinical Ophthalmology is an international, peer-reviewed journal covering all subspecialties within ophthalmology. Key topics include: Optometry; Visual science; Pharmacology and drug therapy in eye diseases; Basic Sciences; Primary and Secondary eye care; Patien Safety and Quality of Care Improvements. This journal is indexed on

\section{Dovepress}

PubMed Central and CAS, and is the official journal of The Society of Clinical Ophthalmology (SCO). The manuscript management system is completely online and includes a very quick and fair peer-review system, which is all easy to use. Visit http://www.dovepress.com/ testimonials.php to read real quotes from published authors. 